\title{
Informing Equity \& Diversity in Primary Care Policy and Practice: Introducing a New Series of Policy Briefs, Commentaries, and Voices in JABFM
}

\author{
Aimee R. Eden, PhD, MPH, Danielle D. Jones, PhD, MPH, \\ Andrew W. Bazemore, MD, MPH, and Yalda Jabbarpour, MD
}

(J Am Board Fam Med 2022;35:190-196.)

Recent events remind us that deeply embedded inequities in health care access and health outcomes are rooted in historically white, and male, systems of power. ${ }^{1,2}$ Authors have documented how, in the United States, medicine was built on racist and patriarchal foundations that excluded and marginalized Black and other people of color and women from entering medicine., Historic (and ongoing), overt (and hidden) systematic oppression of nondominant groups of people, and the related structural determinants of health (including racism, sexism, classism, and heteronormativity), range in impact from individual patient health outcome disparities, to population level health inequities, to health care workforce misrepresentation and discriminatory experiences. ${ }^{5}$ While laudable steps are being taken by many in the medical community to identify and correct remnants of discrimination in the health care system (and in health care research) that have contributed to these inequities, there is much work to be done by all if we are to achieve social justice in medicine. ${ }^{6,7}$ In that spirit, we are launching a new series of JABFM policy briefs and accompanying commentaries with the intention not only of informing key

From the American Board of Family Medicine, Lexington, KY (ARE); American Academy of Family Physicians, Leawood, KS (DDJ); American Board of Family Medicine, Lexington, KY (AWB); Robert Graham Center for Policy Studies, Washington, DC (YJ).

Funding: None.

Conflict of interest: Drs. Eden and Bazemore are employees of the American Board of Family Medicine.

Corresponding author: Aimee R. Eden, PhD, MPH, 1648 McGrathiana Parkway, Suite 550, Lexington, KY 40511 (E-mail: aeden@theabfm.org).

\footnotetext{
See Related Articles on Page 5 and 7 .
}

issues relevant to equity and diversity in primary care policy and practice, but of applying a critical perspective to these topics and being more inclusive of a diverse array of collaborators and authors (Figure 1).

Using our unique data resources, we intend to address a wide range of critical issues. Among them is the lack of diversity, broadly defined, in the medical workforce, including in family medicine. Its absence impacts outcomes for all patients, while conversely, racial/ethnic and other forms of diversity have been associated with better health outcomes. ${ }^{8,9}$ Racial, language, and gender concordance between patients and providers have considerable implications for health equity, and are associated with improved clinical outcomes and higher levels of patient satisfaction. ${ }^{10-12} \mathrm{~A}$ diverse physician workforce is beneficial for the physicians who make up this workforce as well. Without diversity, professional outcomes related to equitable treatment, compensation, and mentorship, among other things, will not improve, and experiences of discrimination and oppression will continue. ${ }^{13-15}$

While the family medicine workforce has diversified in recent decades, it is still far from reflecting the US population it serves. ${ }^{16}$ Understanding the family medicine workforce and how it is changing will help identify ways to become a more inclusive and diverse specialty. Some past policy briefs in JABFM have explored issues related to diversity and equity in the workforce, including differences in hours worked by male and female family physicians ${ }^{17}$ and the racial and ethnic composition of the family medicine workforce over time. ${ }^{18}$ However, our intent in launching the Equity and Diversity in Family Medicine Policy Brief Series is to achieve a more purposeful and sustained approach, using our novel and unique data 


\section{EQUITY \& DIVERSITY IN THE FAMILY MEDICINE WORKFORCE}

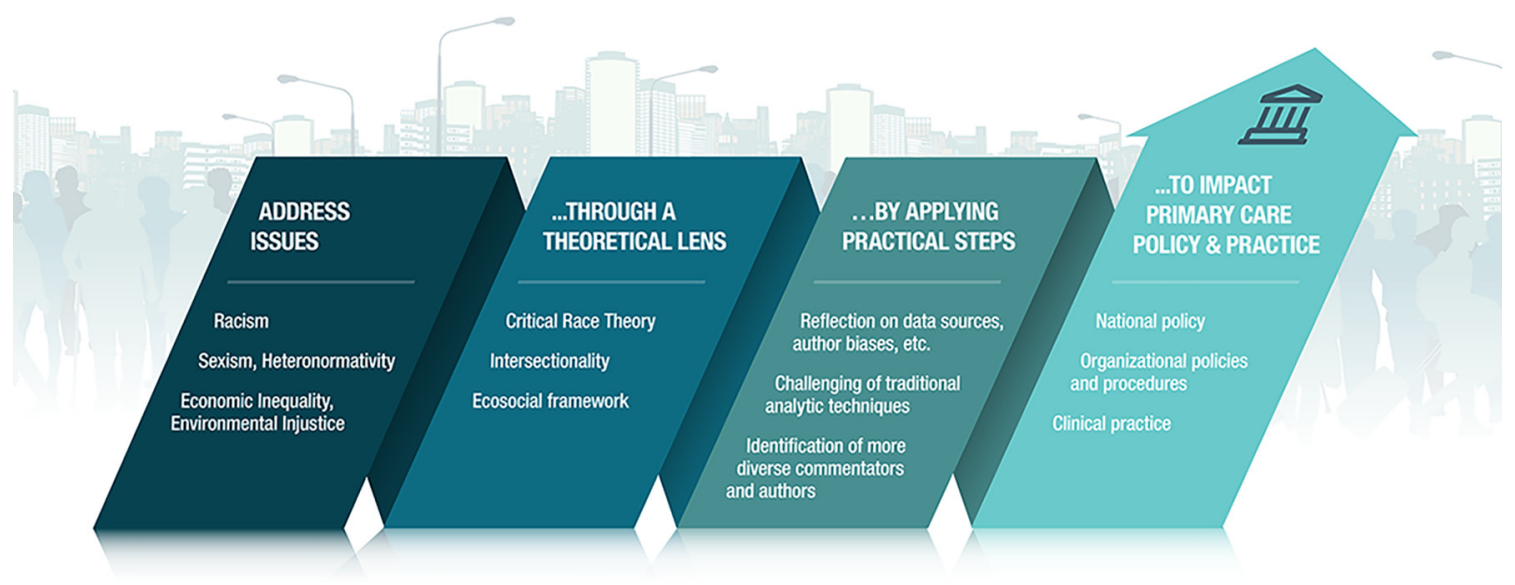

sources and the pairing of a policy brief + commentary format, to informing critical issues in equity and diversity for stakeholders in policy and practice. After reflecting on the insufficient diversity in past writing teams, we are being intentional in seeking new voices and partners. Our initial 3-year plan involves the crafting of at least 9 new policy briefs and paired commentaries dedicated to diversity and equity in the family physician workforce. You will find in this issue two policy briefs to kick off the series: One, on the gender pay gap in the family medicine workforce ${ }^{19}$ and another on languages spoken in clinical practice. ${ }^{20}$ Building on previous diversity and equity work, we plan to study and reflect on the current state of, and the trends over time in, the family medicine workforce, and to examine potential policy implications toward becoming a more equitable and diverse specialty.

\section{Considerations, Reflections, and Limitations}

More and more health workforce research focuses on, or at least considers, issues of equity, justice, diversity and inclusion in the design, implementation, and/or analysis phases, and there are lessons to be learned from this body of growing work. We would like to make some important points relevant to this series but that extend to larger issues around the conduct and presentation of research more broadly, and describe related limitations and challenges that the policy brief series will likely face. First, although much of the series' focus will likely be on racial and ethnic equity, diversity and equity in the workforce include other, intersectional, aspects, both innate and acquired: biological sex, gender identity, sexual orientation, age, language, rural vs urban upbringing, and socioeconomic background/social class, ${ }^{21,22}$ and briefs on these and other topics related to a broad definition of diversity will be welcome. Because such demographic workforce data are not often collected at all, much less collected systematically or with precision, research focusing on some of these areas may be challenging, particularly when applying a traditional research format; for this reason, we intend to be flexible with study design for this policy brief series.

Second, the language that we use to categorize and describe individuals, communities, and populations has serious implications for interpreting and understanding data - and can shape how we approach and make decisions about data collection, analysis, presentation, and dissemination. Language is not static, ${ }^{23}$ and we are at a point in time where critical analyses of how and why certain terminologies are used/abused are pushing us to find more accurate and inclusive, and less harmful, ways to label and describe human variation. ${ }^{24-26}$ Thoughtfully and critically defining, justifying, eliminating, or modifying particular terms used to describe groups of people, such as "underrepresented minority," "nonwhite," "underserved populations," "illegal immigrant," and "transsexual," is an important step toward achieving equity in research. ${ }^{27-29}$ In this policy brief series, we hope to challenge problematic terms and promote a shift to the use of non- (and anti) racist language, as well as 
shifting toward an intersectional attentiveness toward person-first, inclusive language. One related challenge that policy brief authors will face is that because many surveys and questionnaires have not yet made the shift toward using more inclusive and accurate language, researchers may be constrained by the ways the demographic data have been collected. We will be attentive to inclusive language and will apply the guidance and guidelines ${ }^{24,28,29}$ to the extent possible, with the awareness that demographic categories used to collect data are social, political, and economic constructs that do not adequately reflect human variation and experience.

Likewise, the language that we use to describe the underlying reasons for various types of inequity should be accurate. While measuring, and therefore implicating, structural racism as the primary cause of health inequities has gained attention over the last few years, naming racism (at all levels), White supremacism, and White privilege in medicine has been controversial, suppressed, and slow to be openly addressed. ${ }^{30-33}$ And while it is imperative to explore the many ways in which racism causes health outcome inequity, it is equally important to understand how the health care workforce and its hierarchies and composition contributes to and replicates these White, and heterosexual male, systems of power. In this policy brief series, we encourage authors to consider racism, sexism, and heteronormativity when conducting analyses and presenting policy implications of their findings. ${ }^{34}$

Finally, the conduct and process of research, from design to analysis and dissemination, including who conducts and participates in research implementation, is shaped by norms and standards that often go unquestioned and unchallenged. ${ }^{35}$ For example, using "White" as the reference group to which all others are compared can have the effect of normalizing Whiteness and behaviors of White clinicians, while othering people of color. ${ }^{36}$ While policy briefs, by nature, do not allow for authors to reflect on how their own positionality (eg, a White researcher studying minoritized individuals) in a study might impact research decisions, we hope that researchers will take this work on as they design and conduct new studies. ${ }^{37-40}$ We encourage submissions from researchers from diverse backgrounds, to ensure a variety of perspectives and expertise. ${ }^{41} \mathrm{We}$ further hope that this series will provoke innovation in the ways in which research and policy questions are asked, how data are collected and analyzed, and how results are presented. ${ }^{42,43}$ A related challenge for researchers is a limited range of data sources and variables within those sources, as well as a lack of validated measures that capture equity and structural level factors.

\section{Applying Theoretical Frameworks}

The above points illustrate how we hope that this Equity and Diversity in Family Medicine Policy Brief Series can use critical theoretical and conceptual frameworks to ask better research questions, collect better data, and conduct more accurate analyses that attend to inequities in the family medicine workforce, and which have direct implications for addressing disparities in patient outcomes. Here, we summarize critical race theory (CRT) and intersectionality, 2 important theoretical approaches for this work, though we recognize that there exists an array of frameworks that would help lay the groundwork for a methodologically rigorous approach to studying discrimination and health inequities, and which can extend the idea of health equity to issues of physician workforce diversity and equity (eg, ecosocial theory, ${ }^{44,45}$ political economy of health, ${ }^{46,47}$ health equity framework, ${ }^{48}$ life course approach ${ }^{49}$ ).

CRT has become an issue of controversy since being introduced in K-12 education. In light of state legislative bans intended to block its use in education, ${ }^{50,51}$ it is pertinent to consider implications for medical education and training. As a tool, developed in the 1980s by a group of legal scholars of color, for conducting research and practice that examines both contemporary and historic racial phenomena and concepts to generate knowledge about societal inequities and to challenge racial hierarchies, CRT's use within medical education, training, and practice is relatively new. ${ }^{52,53}$ Calls for a CRT approach to medical education have cited the need for physicians to understand structural racism, its historic roots and its implication in creating health disparities. Current curricula describing health disparities, cultural competency and unconscious bias are often limited, incomplete, and lack the critical perspectives needed to understand the social, economic, and historic inequities that create disparities or the solutions to mitigate them. Medical students and trainees continue to receive an education that views race as an intrinsic biological characteristic rather than a social construct, which is known to result in disparate 
diagnostic and treatment decisions. ${ }^{54}$ This education perpetuates the tendency to pathologize patients of color and allows for the disregard of the influence of policies, systems and processes rooted in systematic oppression designed to disenfranchise individuals because of race, gender, class, etc. This disenfranchisement extends to the medical workforce, where certain individuals have been excluded, leading to systemic underrepresentation, and marginalized, leading to discrimination and other negative experiences. ${ }^{5,56}$ Applying CRT in medical education and in health workforce and policy research offers an opportunity to achieve health equity by dismantling the ways in which discrimination is systematically embedded across the medical education continuum, and medicine writ large. ${ }^{57-59}$

Academic medicine has become increasingly focused on integrating intersectionality frameworks into health care, however translation to clinical practice has been minimal due to the lack of understanding of its applicability and approach. ${ }^{60,61}$ Intersectionality theory emerged from African American feminist legal scholarship in the late 1980s/early 1990s as a way to examine how systems produce differential outcomes for individuals based on their multiple social identities and positions within social hierarchies. ${ }^{62}$ The core tenets of intersectionality affirm that human lives cannot be reduced to single characteristics based on race, gender, etc.; human experiences cannot be accurately understood by prioritizing any one single characteristic over another; social categories such as race and gender are social constructed, fluid and flexible; and identities are inseparable and shaped by interactions between social processes and structures influenced by time and place. ${ }^{63}$ Adopting intersectional perspectives challenges individuals to shift their understanding of personal characteristics from being biologically determined to being socially constructed, identify their relationships to and interactions with systems, and critically examine the ways in which policies, processes and mechanisms create inequities. ${ }^{64}$ In health care, applying an intersectionality framework not only to clinical practice and patient outcomes and experiences but also to health service delivery, the composition of the health care workforce, and the experiences of clinicians, provides a mechanism for identifying and addressing disparities and inequities holistically and systematically. ${ }^{65,66}$ In practice, clinicians should aim to reflect on their own intersecting social identities and consider ways in which they shape their diagnostic and treatment decisions and interactions with patients and other health care providers and develop skills to understand how their patients' self-reported social identities may contribute to inequities and health disparities.

\section{Policy Implications}

It is our hope that the policy briefs in this series, and their accompanying commentaries, will be used to inform, influence, challenge, and change practice, policy, organizational culture, and advocacy efforts toward systemic justice. Evidence and incisive commentary alone will not achieve equity, but the absence of each undoubtedly weakens the cause. Decisionmakers hoping to achieve equitable policy must first understand the issues and underlying facts. Credibility and trust are under siege, and reliable sources of information increasingly scarce in contemporary policy dialog. Pairing clear and pithy summaries built from unique and comprehensive data sources with an increasing diversity of author voices to examine critical questions related to diversity and equity will inform and galvanize the creation of a more diverse workforce, better patient outcomes, and greater equity in health care.

To see this article online, please go to: bttp://jabfm.org/content/ 35/1/190.full.

\section{References}

1. Khazanchi R, Evans CT, Marcelin JR. Racism, Not Race, Drives Inequity Across the COVID-19 Continuum. JAMA Netw Open 2020;3:e2019933.

2. Elias A, Ben J, Mansouri F, Paradies Y. Racism and nationalism during and beyond the COVID19 pandemic. Ethnic and Racial Studies 2021;44:783-93.

3. Baker RB. The American Medical Association and Race. AMA Journal of Ethics 2014;16:479-88.

4. Daher Y, Austin ET, Munter BT, Murphy L, Gray K. The history of medical education: a commentary on race. J Osteopath Med 2021;121:163-70. https://www. degruyter.com/document/doi/10.1515/jom-2020-0212/ html.

5. National Academies of Sciences, Engineering, and Medicine; Health and Medicine Division, et al. Board on Population Health and Public Health Practice; Committee on Community-Based Solutions to Promote Health Equity in the United States; Baciu A, Negussie Y, Geller A, eds. Communities in Action: Pathways to Health Equity. Washington (DC): 
National Academies Press (US); 2017 Jan 11. 3, The Root Causes of Health Inequity. Available from: https:/www.ncbi.nlm.nih.gov/books/NBK425845/.

6. Madara JL. Reckoning With Medicine's History of Racism. American Medical Association. 2021. Accessed October 18, 2021 from https:/www.ama-assn.org/ about/leadership/reckoning-medicine-s-history-racism? utm_source=Sailthru\&utm_medium=email\&utm_ campaign=Newsletter $\% 20$ Weekly\%20Roundup:\% 20Healthcare\%20Dive:\%20Daily\%20Dive\% 200220-2021\&utm_term=Healthcare \%20Dive \% 20 Weekender.

7. Wilbur K, Snyder C, Essary AC, Reddy S, Will KK, Saxon M. Developing workforce diversity in the health professions: a social justice perspective. Health Professions Education 2020;6: 222-9.

8. Jackson CS, Gracia JN. Addressing health and health-care disparities: the role of a diverse workforce and the social determinants of health. Public Health Rep 2014;129 Suppl 2:57-61.

9. Kelly Blake K, Garrison NA, Fletcher FE, et al. Rationales for expanding minority physician representation in the workforce: a scoping review. Med Educ 2018;52:925-35.

10. Takeshita J, Wang S, Loren AW, et al. Association of Racial/Ethnic and Gender Concordance Between Patients and Physicians With Patient Experience Ratings. JAMA Netw Open 2020;3:e2024583.

11. Moreno G, Walker KO, Morales LS, et al. Do physicians with self-reported non-English fluency practice in linguistically disadvantaged communities? J Gen Intern Med 2011;26:512-7.

12. Garcia ME, Bindman AB, Coffman J. Languageconcordant primary care physicians for a diverse population: the view from California. Health equity 2019;3:343-9.

13. Eden AR, Chesluk BJ, Hansen ER, Brock A, Bernabeo EC, Peterson LE. The Role of Gender in the Experience and Impact of Recertification Exam Preparation: A Qualitative Study of Primary Care Physicians. J Womens Health (Larchmt) 2020;29: 1401-9.

14. Filut A, Alvarez M, Carnes M. Discrimination toward physicians of color: a systematic review. J Natl Med Assoc 2020;112:117-40.

15. Newman C. Time to address gender discrimination and inequality in the health workforce. Hum Resour Health 2014;12:25-1.

16. Xierali IM, Nivet MA, Gaglioti AH, Liaw WR, Bazemore AW. Increasing family medicine faculty diversity still lags population trends. J Am Board Fam Med 2017;30:100-3.

17. Wilkinson E, Coffman M, Petterson S, Jabbarpour Y. Gender differences in reported weekly work hours among family physicians. J Am Board Fam Med 2020;33:653-4.

18. Peabody MR, Eden AR, Douglas M, Phillips RL. Board certified family physician workforce: Progress in racial and ethnic diversity. J Am Board Fam Med 2018 Nov 1;31:842-3.

19. Jabbarpour Y, Wendling A, Taylor MK, Bazemore AW, Eden AR, Chung Y. Family medicine's gender pay gap. J Am Board Fam Med 2022;35:7-8.

20. Eden AR, Bazemore AW, Morgan ZJ, Jabbarpour Y. Family physicians increasingly deliver care in diverse languages. J Am Board Fam Med 2022;35:5-6.

21. Quinn GP, Gwede CK, Meade CD. Diversity beyond race and ethnicity: Enhancing inclusion with an expanded definition of diversity. Am J Bioeth 2018;18:47-8.

22. Health Resources and Services Administration. Policy Statement on Workforce Diversity and Inclusion. Accessed October 2, 2021 from https:// www.hhs.gov/guidance/sites/default/files/hhs-guidancedocuments//diversity.pdf.

23. Alliance for Healthier Communities. Inclusive and Empathetic Language Use Guidelines. Accessed October 2, 2021 from https://educ.queensu.ca/sites/ webpublish.queensu.ca.educwww/files/files/Inclusive \% 20Language-Use\%20Guide\%20-\%202020.pdf.

24. Flanagin A, Frey T, Christiansen SL, AMA Manual of Style Committee. Updated Guidance on the Reporting of Race and Ethnicity in Medical and Science Journals. JAMA 2021;326:621-7.

25. Braveman P, Parker Dominguez T. Abandon "Race." Focus on Racism. Front Public Health 2021; 9:689462.

26. Carrotte ER, Vella AM, Bowring AL, Douglass C, Hellard ME, Lim MS. "I am yet to encounter any survey that actually reflects my life": a qualitative study of inclusivity in sexual health research. BMC Med Res Methodol 2016;16:86-0.

27. Likis FE. Inclusive Language Promotes Equity: The Power of Words. J Midwifery Womens Health 2021;66:7-9.

28. Centers for Disease Control and Prevention. Health Equity Style Guide for the COVID-19 Response: Principles and Preferred Terms for NonStigmatizing, Bias-Free Language. Accessed October 2, 2021 from https://ehe.jhu.edu/DEI/ Health_Equity_Style_Guide_CDC_Reducing_Stigma. pdf.

29. Herman JL. Best practices for asking questions to identify transgender and other gender minority respondents on population-based surveys Los Angeles: The GeniUSS Group; 2014.

30. Groos M, Wallace M, Hardeman R, Theall KP. Measuring inequity: a systematic review of methods used to quantify structural racism. Journal of Health Disparities Research and Practice 2018;11:13. 
31. Franks NM, Gipson K, Kaltiso SA, Osborne A, Heron SL. The Time Is Now: Racism and the Responsibility of Emergency Medicine to Be Antiracist. Ann Emerg Med 2021;78:577-86.

32. Jackson JL, Bates C, Asch SM, Roberts R, Clarkson JR. How Can Medical Journals Promote Equity and Counter Racism? J Gen Intern Med 2021;36:2919-21.

33. Boyd RW, Lindo EG, Weeks LD, McLemore MR. On racism: a new standard for publishing on racial health inequities. Health Affairs Blog 2020;10: (10.1377).

34. Homan P. Structural sexism and health in the United States: A new perspective on health inequality and the gender system. Am Sociol Rev 2019;84:486-516.

35. Baer RD, Arteaga E, Dyer K, et al. Concepts of race and ethnicity among health researchers: patterns and implications. Ethn Health 2013;18:211-25.

36. Daniels J, Schulz AJ. Constructing whiteness in health disparities research. In Schulz A. J., Mullings L. (Eds.), Health and illness at the intersections of gender, race and class (pp. 89-127). 2006. San Francisco, CA: Jossey-Bass Publishing. 36.

37. Godwin A. Sitting in the Tensions: Challenging Whiteness in Quantitative Research. Studies in Engineering Education 2020;1:78-82.

38. Kamenou N. Methodological considerations in conducting research across gender,'race', ethnicity and culture: a challenge to context specificity in diversity research methods. The International Journal of Human Resource Management 2007;18:19952010 .

39. Coleman BR, Collins CR, Bonam CM. Interrogating whiteness in community research and action. Am J Community Psychol 2021;67:486-504.

40. Liu H. Diversity Beyond Whiteness: The Possibilities for Anti- Racist Diversity Research. In The Routledge Companion to Organizational Diversity Research Methods 2020 Oct 13 (pp. 24-35). Routledge.

41. Maduakolam E, Madden B, Kelley T, Cianciolo AT. Beyond diversity: envisioning inclusion in medical education research and practice. Teach Learn Med 2020;32:459-65.

42. Ross PT, Hart-Johnson T, Santen SA, Zaidi NL. Considerations for using race and ethnicity as quantitative variables in medical education research. Perspect Med Educ 2020;9:318-23.

43. Ioannidis JPA, Powe NR, Yancy C. Recalibrating the Use of Race in Medical Research. JAMA 2021;325:623-4.

44. Krieger N. Epidemiology and the web of causation: has anyone seen the spider? Soc Sci Med 1994;39:887-903.

45. Krieger N. Methods for the scientific study of discrimination and health: an ecosocial approach. Am J Public Health 2012;102:936-44.
46. Doyal L. What makes women sick: Gender and the political economy of health. Macmillan International Higher Education; 1995 Jun 19.

47. Harvey M. The Political Economy of Health: Revisiting Its Marxian Origins to Address 21stCentury Health Inequalities. Am J Public Health 2021;111:293-300.

48. Dover DC, Belon AP. The health equity measurement framework: a comprehensive model to measure social inequities in health. Int J Equity Health 2019;18:1-2.

49. Braveman P. What is health equity: and how does a life-course approach take us further toward it? Matern Child Health J 2014;18:366-72.

50. Ray R, Gibbons A. Brookings. Why are states banning critical race theory? August 2021. Accessed October 2, 2021 from https://www.brookings.edu/ blog/fixgov/2021/07/02/why-are-states-banningcritical-race-theory/.

51. American Medical Association. Organizational Strategic Plan to Embed Racial Justice and Advance Health Equity, 2021-2023. Accessed October 2, 2021 from https://www.ama-assn.org/system/files/ 2021-05/ama-equity-strategic-plan.pdf.

52. Tsai J, Crawford-Roberts A. A call for critical race theory in medical education. Academic Medicine 2017;92:1072-3.

53. Braun L. Theorizing race and racism: preliminary reflections on the medical curriculum. Am J Law Med 2017;43:239-56.

54. Amutah C, Greenidge $\mathrm{K}$, Mante A, et al. Misrepresenting race-the role of medical schools in propagating physician bias.

55. Periyakoil VS, Chaudron L, Hill EV, Pellegrini V, Neri E, Kraemer HC. Common types of genderbased microaggressions in medicine. Academic Medicine 2020;95:450-7.

56. Overland MK, Zumsteg JM, Lindo EG, et al. Microaggressions in clinical training and practice. PM R 2019;11:1004-12.

57. Gillborn D, Warmington P, Demack S. QuantCrit: education, policy, 'Big Data' and principles for a critical race theory of statistics. Race Ethnicity and Education 2018;21:158-79.

58. Atwood E, López GR. Let's be critically honest: Towards a messier counterstory in critical race theory. International Journal of Qualitative Studies in Education 2014;27:1134-54.

59. Ford CL, Airhihenbuwa CO. Commentary: Just What is Critical Race Theory and What's it Doing in a Progressive Field like Public Health? Ethn Dis 2018;28:223-30.

60. Davy Z. The promise of intersectionality theory in primary care. Quality in Primary Care 2011;19: 279-81. 
61. Eckstrand KL, Eliason J, St Cloud T, Potter J. The priority of intersectionality in academic medicine. Acad Med 2016;91:904-7.

62. Hankivsky O. Women's health, men's health, and gender and health: Implications of intersectionality. Soc Sci Med 2012;74:1712-20.

63. Bauer GR. Incorporating intersectionality theory into population health research methodology: Challenges and the potential to advance health equity. Soc Sci Med 2014;110:10-7.
64. Powell Sears K. Improving cultural competence education: the utility of an intersectional framework. Med Educ 2012;46:545-51.

65. Keshet Y, Popper-Giveon A, Liberman I. Intersectionality and underrepresentation among health care workforce: the case of Arab physicians in Israel. Isr J Health Policy Res 2015;4:18-3.

66. Karbeah JM. Wage Discrimination within Health care Professions: An Intersectional Analysis. Health Serv Res 2020;55:70-1. 